Tesis. Año 14, 13(17), 2020, 37-50

\title{
Personajes colectivos e individuales en Los rúos profundos de José María Arginedas
}

\author{
Carlos Huamán ${ }^{1}$ \\ huamanlopez@yahoo.com.mx
}

\section{Resumen}

En la novela Los ríos profundos de José María Arguedas hay una singular configuración de los personajes vinculados con el universo cultural quechua-andino. Es así que tanto el personaje central, como los secundarios, suelen convertirse en voceros de colectivos o de individuos que, dependiendo del caso, se convierten en representaciones mítico-simbólicos.

Palabras clave: narrativa, ficción, personajes, colectivos, individuales.

\section{Abstract}

In Los rios profundos (Deep Rivers), novel by Peruvian José María Arguedas, there is a unique configuration of the characters linked to the Quechua-Andean cultural universe. Thus, both the central and secondary characters tend to become spokesmen for collectives or individuals that, depending on the case, become mythical-symbolic representations.

Keywords: narrative, fiction, characters, collectives, individuals. 


\section{Personajes colectivos e individuales en Los réos profundos de José María Arginedas}

\section{Lo individual y lo transindividual}

Si bien la historia de Los ríos profundos (1958), del escritor peruano José María Arguedas (Andahuaylas, 1911-Lima, 1969), se construye a partir de la memoria y la conciencia de Ernesto - en su doble papel de personaje y narrador-, eso no significa que la historia se limite al plano individual. En esta novela, la relación entre lo individual y lo social es dialéctica. Ambos conceptos están imbricados totalmente; el uno no existe sin lo otro. Lo individual está hermanado con lo social, porque ambos responden al dinamismo del proceso histórico que los ha generado. Como menciona Mario Vargas Llosa: "la literatura atestigua así sobre la realidad social y económica, por refracción, registrando las repercusiones de los acontecimientos históricos y de los grandes problemas sociales a un nivel individual: es la única manera de que el testimonio literario sea viviente y no cristalice en un esquema muerto" (Vargas, 1972, p. 54). Prueba de esto es que Ernesto, el narrador-protagonista, busca conjuntar sus reflexiones sociales con sus motivaciones de orden psicológico o personal:

— ¡Que viva doña Felipa! ¡Patibambapak’! — gritaron las mujeres que salían tras de las mulas.

— ¡Doña Felipa! ¡Doña Felipa! —corearon todas, despidiéndose de la cabecilla.

Ella no se había olvidado de los indefensos, de los "pobres" de Patibamba. Con la violencia del éxito ninguna otra se había acordado de ellos.

-Despacio van a repartir - dijo en quechua, dirigiéndose a la comisión.

El reparto continuaba aún en el patio, pero yo no dudé; salí tras de las mujeres que iban a Patibamba. Como ellas, tenía impaciencia por llegar. Una inmensa alegría y el deseo de luchar, aunque fuera contra el mundo entero, nos hizo correr por las calles. (Arguedas, 1973, p. 103) 
En la novela encontramos dos niveles de expresión: el primero es el referido por la voz individual de Ernesto, el segundo, expresado por la colectividad; es decir, el pueblo. Aunque la narración es dirigida por la conciencia de Ernesto, este no se ubica por encima de la colectividad. El conjunto presenta un discurso que responde a sus propias motivaciones; el grupo tiene voz propia a pesar de la existencia de la conciencia unificadora del narrador-protagonista. La trama de Los rios profundos muestra intervalos rítmicos de avance y retroceso - la lógica de la narración oral-. El clímax lleva hasta el agotamiento; de ahí se inicia nuevamente la renovación. "Mi corazón palpitaba con gran fatiga..." (Arguedas, 1973, p. 106) dice Ernesto debido a la excitación que le produce el unirse a la fuerza y la voz colectivas.

La mirada panorámica y profunda de Ernesto, aunada a su particular sensibilidad, contribuye a mostrar nítidamente el sentir del pueblo oprimido, quien expresa su dolor y su alegría a través de la palabra y la música. Además, el protagonista-narrador se identifica profundamente con la causa de los oprimidos; vive y siente los padecimientos de la colectividad: "Mientras repartían la sal sentí que mi cuerpo se empapaba de sudor frío” (Arguedas, 1973, pp. 105-106). Este aspecto le permitirá establecer un vínculo con otras figuras representativas de la novela - por ejemplo, con doña Felipa, la chichera que lidera el motín de la sal一.

El pasado personal de Ernesto está unido irremediablemente al pasado colectivo indígena debido a su identificación con la cultura andina y, por supuesto, a su infancia transcurrida en el ayllu. Ahora bien, el sufrimiento personal se retrata -identifica - en el sufrimiento general de los oprimidos. Este hecho es el hilo que vincula individuo y colectividad en una unidad indivisible:

Yo tenía catorce años; había pasado mi niñez en una casa ajena, vigilado siempre por crueles personas. El señor de la casa, el padre, que tenía ojos de párpados enrojecidos y cejas espesas; le placía hacer sufrir a los que dependían de él, sirvientes y animales. Después, cuando mi padre me rescató y vagué con él por los pueblos, encontré que en todas partes la gente sufría. La "María Angola" lloraba, quizás, por todos ellos, desde el Cuzco. (Arguedas, 1973, p. 19)

Desde temprana edad, Ernesto descubre que el sufrimiento, el abandono y la soledad no le son exclusivos; esos problemas son inherentes a la gran mayoría de la población serrana —indios y mestizos-, la cual ha sido vejada y desposeída desde la Colonia.

Ernesto ingresa a "un mundo cargado de monstruos y de fuego" (Arguedas, 1973, p. 42) donde la lucha por asirse a la colectividad se sostiene con violencia. Los hervores del contexto se hunden en el yawar mayu de una historia plagada de chiririnkas. Qué monstruo podría contra un individuo protegido 
por el K'arwarasu. Ni el fuego de los infiernos, ni la maldición de Linares, ni la imagen de los condenados que padecen en la oscuridad con sus cadenas tintineantes hacen de él sangre de pulga ni alimento del tifus. Este combate - aparentemente individual - se establece en un espacio que compromete a la totalidad del cosmos. Como sostiene Cornejo Polar, Los rios profundos tiene "como supuesto una concepción de universo entendido como totalidad coherente, compacta, absolutamente integrada. El contraste entre esa concepción y la realidad de un mundo desintegrado y conflictivo es el núcleo de la novela" (Cornejo, 1973, p. 100).

En Los ríos profundos, la conciencia observadora - Ernesto-muestra las relaciones del yo con el mundo circundante, un mundo cargado de crueldad e injusticia y, a veces, también de inocencia y magia. Por otra parte, su pertenencia al colectivo propicia que las experiencias individuales superen al plano supraindividual. En el narrador-protagonista se gesta, por tanto, un proceso de transindividualización. Mediante este, el discurso de Ernesto se convierte en una suerte de voz colectiva.

Para explicar la idea de sujeto colectivo en la sociedad andina podemos utilizar una analogía con los trabajos pictográficos y artesanales de la zona, ya que estos responden al ideal con que fue construida Los rios profundos. Las tablas de Sarhua son pinturas que representan escenas de la vida cotidiana - trabajo, fiestas, religión - de las comunidades quechuas, especialmente las de la zona sur andina peruana. El personaje principal de esas obras tiene vinculación directa con el resto de los personajes representados. El rostro, por ejemplo, tiene cierta proximidad a otros. Además, la visión de los colores une a hombres y mujeres, por lo que la masa se compacta. Esto propicia que sea la multitud quien narre la historia. El arte indígena tiene esa inclinación a decir algo teniendo en cuenta el todo. La autoría personal, por lo tanto, desaparece; surge el llamado "anonimato". Para los indígenas, ese autor anónimo se llama ñuqanchik - nosotros-.

La identificación de Ernesto con la colectividad tiene su referente en la concepción andina de la sociedad como sujeto colectivo. Martin Lienhard explica que

Ernesto, con su cosmovisión hispano-quechua aparece en una lectura "andina" como un sujeto colectivo, representante de los nuevos sectores cultos de origen andino. Bajo este ángulo, la novela anuncia una transformación social cuyo éxito depende de la alianza entre los colonos de la hacienda del último capítulo, los mestizos urbanos (las chicheras de los capítulos centrales) y los sectores apenas mencionados, únicos capaces de entender la realidad total del país y de indicar las soluciones políticas necesarias. (Lienhard, 1990, p. 202) 
Por consiguiente, la solución a la explotación y la desigualdad social no puede provenir únicamente de los indios; solo la alianza de los sectores marginados puede modificar la situación de oprobio e injusticia. Sin dicha unión, será imposible construir una alternativa de transformación que convenga a las mayorías. En este sentido, el pasaje donde las chicheras distribuyen la sal resulta paradigmático, pues ahí se plantea la manera de distribuir los bienes materiales monopolizados por los sectores hegemónicos. Recordemos que los comerciantes se habían apropiado de la sal con la finalidad de lucro:

- Para los pobres de Patibamba tres costales - dijo, como para sacudirme.

Hasta ese momento se había repartido ya la mayor parte de los sacos de sal, y el patio se veía despejado.

Ante la orden, casi inesperada, varias mujeres fueron a ver el corral de la Salinera.

Encontraron cuarenta mulas aún aperadas. La noticia desconcertó a las cholas. Pero la cabecilla ordenó que arrearan tres al patio. No hizo ningún comentario.

Mientras las repartidoras seguían llenando las mantas de las mujeres con grandes trozos de sal, alegremente, se dedicaron a preparar las cargas para los "colonos" de Patibamba. (Arguedas, 1973, p. 102)

Doña Felipa, la principal dirigente del motín, muestra tener plena conciencia de que no solo las chicheras y los mestizos son oprimidos; los colonos, "gusanos" de la sociedad andina, lo son aún más. Ese conocimiento explica por qué, en el reparto de la "pequeña” riqueza confiscada, debe incluírselos. La visión de Ernesto acerca de la realidad es clave para que, a pesar de las marcadas contradicciones existentes, la sociedad andina se reconstruya como un todo integral.

La capacidad de integración y movilización de las chicheras - y posteriormente de los colonos - no surge espontáneamente; se desencadena a través de las fuerzas anímicas contenidas en el pasado histórico indígena. El encuentro de Ernesto con ese pasado se da mediante un proceso de integración a la colectividad.

Ernesto deja de ser un individuo aislado para integrarse al personaje-masa del cual nos habló Vallejo en Los Heraldos negros (1918). El levantamiento de las chicheras es un cuadro donde lo individual se compacta en un sujeto plural.

Cerca de Huanupata muchos hombres y mujeres se sumaron a la comisión. La gente salía de las casas para vernos, corrían por las calles transversales para mirarnos desde las esquinas. 
Así llegamos a la carretera, al ancho camino polvoriento de la hacienda. Era ya un pueblo el que iba tras de las mulas, avanzando a paso de danza. Las chicheras seguían cantando con el rostro sonriente. (Arguedas, 1973, p. 104)

E1 levantamiento se convierte en una fiesta popular donde la alegría del pueblo inunda las calles de Abancay y el barrio de Huanupata. Las chicheras no están solas; a ellas se unen indios y mestizos. Todos muestran una gran capacidad para incluir a quienes se identifican con la causa y tienen conciencia de la realidad.

Entonces, una de las mestizas empezó a cantar una danza de carnaval; el grupo la coreó con la voz más alta.

Así, la tropa se convirtió en una enorme comparsa que cruzaba a carrera por las calles. La voz del coro apagó todos los insultos y dio un ritmo especial, casi de ataque, a los que marchábamos a Patibamba. Las mulas tomaron el ritmo de la danza y trotaron con más alegría. Enloquecidas de entusiasmo, las mujeres cantaban cada vez más alto y más vivo. (Arguedas, 1973, p. 103)

La rebelión cobra fuerza, se levanta como incendio que amenaza con llevarse a la hacienda entre sus llamas. Ernesto "arde" con el grupo hasta desvanecerse. No termina desmayado debido a un sentimiento de repugnancia, miedo o desilusión — como dijera Sara Castro (1973, p. 98)—; su alejamiento es producto del desgaste que exige toda subversión encaminada a la eliminación de los privilegios de los poderosos.

Una vez que el motín culmina exitosamente — con el reparto de la sal— la celebración no se hace esperar en el barrio de Huanupata. Indios y mestizos confirman su compromiso con el movimiento. La alegría es una fuerza que no solo se alimenta de gritos; también se expresa con bailes que dibujan voces unísonas al ritmo de huaynos sonoros y corazonados. ¿De dónde habían venido tantos mestizos e indios al barrio de las chicherías? Indudablemente, desde los rincones donde la miseria teje alas de libertad y justicia. Este hecho nos recuerda un pasaje de Todas las sangres donde la tierra enciende sus temblores de avance y se oyen los tamboreos de las piedras en el interior de la mama pacha. Se trata también del avance del hombre hacia el mismo hombre:

Impusieron el canto en la chichería. Desde el interior empezaron a corearlo. Luego bailaron todos con esa melodía. Zapateaban a compás. Los descalzos, los de ojotas y los de zapatos golpeaban el suelo brutalmente. Los talones de los descalzos sonaban hondo; el cuero de las ojotas palmeaba el suelo duro y los datos martilleaban. Parecía que molían las palabras del huayno. (Arguedas, 1973, p. 109) 
Ernesto llega a la chichería con el afán de unirse a los festejos, pero no es admitido como parte del grupo. Posiblemente, el rechazo ocurre porque sus rasgos mistis marcan una distancia insalvable. Recordemos, empero, que la euforia desatada durante el motín de Abancay no repara en personalidades, ya que es la expresión del todo colectivo. El hecho de que sea excluido en un movimiento social caracterizado por la unión de distintas clases sociales solamente revela hasta qué punto sus rasgos mistis le impiden llevar a cabo su deseo último: ser parte del pueblo.

El exitoso desarrollo de la sublevación mestiza de Abancay paulatinamente genera un gran temor entre los miembros del grupo misti. Obviamente, les preocupa que los mestizos se rebelen; pero la idea de que el enojo causado por el acaparamiento de la sal redunde en la unión de indios y mestizos, resulta totalmente aterrador. Es por ese motivo que la única solución posible, una vez que las fuerzas policiales resultan incapaces de calmar la situación, es solicitar la intervención del ejército. La llegada de las fuerzas militares es una medida extrema que evidencia tanto la fuerza del movimiento popular como el miedo de las clases privilegiadas. Pero ni la intervención de estas ni la del padre Linares pueden impedir que los ríos desborden sus aguas hasta llenar de temblores a los mistis cristianos.

A pesar de que los soldados despojan a las sublevadas de la sal y logran, además, rescatar las armas robadas, el éxito del motín es indudable. El llanto ocasionado por el sentimiento de injusticia es pasajero; perdura la sensación de que el atrevimiento es posible. A partir de esto es factible advertir que también la figura de doña Felipa trasciende el plano individual para convertirse en la portadora de un deseo colectivo que anhela la transformación de la realidad. La chichera, en ese momento, emerge como un mito.

Sin duda este personaje cobra singular importancia debido a que se convierte en la luminaria que impulsará la resistencia indígena. Además, su talante mítico se revela en su promesa de regresar para hacer justicia y devolver la dignidad a los sometidos. Indudablemente, este hecho está relacionado con la imagen del Inkarri, el dios indio descuartizado cuyo regreso, para el universo indio, es una seguridad plena.

Ya Mircea Eliade señalaba que mitos como este no pueden ser considerados "falsos" o inventos, tal como se obligó a pensar durante la Colonia. Sostenía que "el mito relata una historia sagrada que tuvo lugar en el comienzo del tiempo. Pero más que relatar una historia equivale a revelar un misterio, pues sus personajes no son hombres, sino dioses o héroes civilizadores" (Eliade, 1967, p. 106). A este respecto, Arguedas señaló que el "origen de las cosas que existen mediante historia de dioses” (Arguedas, 1964, p. 10) ayuda a dar explicación a las situaciones complicadas. En este caso, el mito andino ayuda a colegir el significado profundo de la huida de la mestiza a la selva, un ocultamiento del 
cual volverá —en cualquier momento- para salvar del oprobio a los suyos. Esa razón hará posible la articulación de una historia que los incluya de tal manera que, en el decurso del tiempo, los hijos "contarán asimismo a sus hijos muchas historias que explican de qué modo su ser, de poderes divinos, enseñó al hombre a fabricar sus casas y utensilios, cómo les enseñó a sembrar las plantas, y por qué motivo apareció la muerte" (Arguedas, 1964, p. 10).

En gran medida, la importancia de los mitos radica en su capacidad para explicar la realidad, es decir, el presente. Ahora bien, esa actualidad solo es inteligible debido a que se encuentra vinculado a un pasado y a un futuro, es decir, porque forma parte de una secuencia lógica. Por tanto, cuando se analiza el presente, es preciso advertir aquellos rasgos que revelan la presencia de lo mítico, pues se trata de auténticos signos que deben ser apropiadamente decodificados. En otras palabras, lo mítico se revela al hombre a través de una suerte de epifanía mediante la cual es factible observar los significados ocultos por lo meramente aparente. Ese es el caso de doña Felipa en tanto héroe mítico.

La lideresa del motín de Abancay revela una serie de características excepcionales totalmente ajenas a su condición de humilde mestiza comerciante de chicha. El desarrollo de la rebelión le otorga el cariz de invencibilidad aunque haya sido derrotada militarmente- e incluso el de la inmortalidad, ya que su fuga se convierte en un triunfo que, en cierta forma, anuncia su regreso triunfal. El poderío militar de los mistis hace prácticamente imposible que una improvisada revuelta mestiza y campesina tenga alguna mínima esperanza de éxito. El posible retorno de doña Felipa es, para el indio, esa fuga que representa un retiro temporal, el tiempo necesario para que la heroína recupere sus fuerzas. Esto evidencia que, en el imaginario indígena, la historia es una línea continua donde la posibilidad de la restauración es un hecho que llegará necesariamente. La utopía, entonces, es el tiempo latente de espera. ${ }^{2}$

La hazaña de doña Felipa tiene una particular importancia; su huida, que anuncia su mítico regreso, demuestra que la lucha no ha sido concluida. El motín de las chicheras no es el clímax de la novela; la revuelta social solamente es el anuncio - mítico- de otro evento donde el personaje colectivo descubrirá su rostro para vencer a un enemigo invisible - solo hasta cierto punto, ya que la peste tiene rostro y cuerpo en el pensamiento mágico-religioso de los indios-, la peste.

Desde Ninabamba — campo de fuego-el tifus se expande por todo el universo de la narración. La amenaza democratiza un espacio totalmente escindido desde la perspectiva racial y económica. La peste no discrimina; ataca tanto a indios y mestizos como a blancos. Los conductores de este mal altamente contagioso, surgido en el seno de la extrema miseria, son los piojos. El hecho de que el peligro que amenaza a todos los habitantes del Ande sea una suerte de ejército que se incuba en las cabezas de los indios, presenta un evidente cariz 
simbólico. Por un lado, los blancos temen que sus vidas sean cercenadas por ese ejército de piojos en la misma forma en que temen a la fuerza justiciera de los "débiles"; por el otro, dado que se trata de una enfermedad generada por la miseria, la existencia de esos piojos solamente se explica como un mal originado por los ricos que quema hasta la muerte el cuerpo de los pobres.

Gracias a la peste, la imagen de sumisión de los colonos deja de ser tal. El tifus los unifica y, paradójicamente, los engrandece a tal punto que son capaces de tomar la ciudad y con ella la iglesia, símbolo del poder misti. Ni siquiera el poderoso e invencible ejército es capaz de detener el avance de esas hordas de menesterosos atacados por la peste. La exigencia de los colonos para que el padre oficie una misa cuya finalidad es la de salvar a los pobres tiene un talente evidentemente simbólico: el pueblo, acostumbrado a obedecer las órdenes de poder, ahora exige que los aparatos del poder — la Iglesia y el dios cristianocumplan con su función.

$\mathrm{El}$ temor, una emoción bien conocida por los indios y mestizos gracias a su papel de subalternos, se convierte en la chispa que hacer arder los deseos de unificación y, por ende, incrementa su capacidad para destruir esos muros sociales que los separan. El miedo se convierte, pues, en el motor que guía la revuelta. Después de la enérgica petición hecha por los humildes pobladores del Ande, al "santo padre de Abancay" solo tiene una posibilidad: oficiar la misa. La petición es tan férrea que incluso el padre debe ignorar la oposición de los vecinos blancos de Abancay, quienes movilizan la fuerza policial para evitar que los colonos ingresen a la iglesia e infesten, por ende, a la ciudad con sus piojos. La fuerza comunal resulta triunfante. Pobres y piojos llegan a la iglesia, pobres y piojos reciben bendición.

El episodio de la peste presenta una significación oculta. Su lógica $-\mathrm{y}$ la de la novela en general - responde al orden mítico propio de la cosmovisión andina. La unión de los hombres frente a la peste y el destierro de esta gracias a la fuerza común revelan que la conformación de Los ríos profundos responde a una idea del mundo distinta de la occidental. Arguedas explica cuál es el significado oculto en el episodio y, por ende, en la novela:

La tesis era ésta: esta gente se subleva por una razón de orden enteramente mágico; ¿cómo no harán, entonces, cuando luchen por una cosa mucho más directa como sus propias vidas, que no sea ya una creencia de tipo mágico?... Esta fue la tesis de la novela y me desesperaba cuando los críticos comentaban el libro y no veían esto... Hasta que felizmente en dos comentarios apareció claramente la exposición de esta tesis. (Arguedas, 1969, p. 239)

La construcción imaginaria de la escena novelesca exige que el lector advierta la fuerza mágica en torno al ambiente. El hecho mismo de escuchar los 
rezos y las imprecaciones a la peste contribuye a establecer un clima violento en el cual la fuerza sobrenatural se hace presente:

Oí, de repente, otros gritos, mientras concluía la oración. Me acerqué a la puerta. La abrí y salí al corredor. Desde allí escuché mejor las voces.

— ¡Fuera peste! ¡Way jiebre! ¡Wáaay...!

— ¡Ripuy, ripuy! ¡Kañask’aykin! ¡Wáaay...!

Lejos ya de la plaza, desde las calles, apostrofaban a la peste, la amenazaban.

Las mujeres empezaban a cantar. Improvisaban la letra con la melodía funeraria de los entierros. (Arguedas, 1973, p. 242)

Desde el internado, Ernesto escucha los rezos y los cantos de los colonos. Confía en que estos tendrán un efecto positivo, es decir, que lograrán aplacar a la enfermedad gracias al poder que la cosmovisión andina atribuye a las palabras. Por otra parte, para el pensamiento mágico asumido por Ernesto, el pueblo es un toro encadenado que lucha por salir de las entrañas del cerro donde está - "El canto de los wak'rapukus subía a las cumbres como un coro de toros encelados e iracundos" (Arguedas, 1973, p. 35)—. Obviamente, las cadenas simbolizan la opresión que sufre el pueblo indio a manos de los mistis. Por ese motivo, en el alzamiento de los colonos, Ernesto "vislumbra la salvación del pueblo quechua encadenado" (Urello, 1974, p. 148). El protagonista de Los ríos profundos revela, de esta manera, el significado oculto en la novela arguediana: la esperanza en la restauración del orden perdido con la llegada del hombre europeo.

Ernesto también emplea la analogía entre los hombres y los animales para describir el accionar de los sublevados: "Los colonos subían, verdaderamente como una mancha de carneros; de miles de carneros..." (Arguedas, 1973, p. 239) Esta imagen establece una relación por demás apropiada. Los colonos han dejado atrás su soledad y recuperado la memoria colectiva que les había sido arrebatada. Ahora, gracias a la energía surgida de la colectividad, es posible vencer a las fuerzas sociales contrarias. Como bien señala Ariel Dorfman en Imaginación y violencia en América Latina, la rebelión acaecida en Abancay no es un

resultado casi mecánico de abusos inaceptables, sino como una ofensiva decidida por parte de los indígenas por instaurar un nuevo orden social y humano, cuyas raíces futuras están en el ser mitológico del indio. No se 
trata de la re-acción biológica, el perro que muerde de tanto que lo han pateado, sino de acción originaria, política y militarmente originaria... Rebelión inevitable, indispensable, esencial, necesaria. (Dorfman, 1972, p. 224)

Evidentemente, tanto los objetivos como las motivaciones que propician las dos revueltas sociales narradas en Los rios profundos propician un arduo debate. Desde nuestra perspectiva, el problema gira en torno a la importancia que el mito tiene en el surgimiento de movimientos sociales en el Ande. Dicha relación ha sido cuestionada por algunos de los mayores estudiosos de la obra arguediana. Por ejemplo, William Rowe plantea que "el mito es esencial en la cultura quechua pero también puede ser un obstáculo. Se oculta esa contradicción al tornar la motivación de los colonos en un mito, como si un mito fuera el origen de su acción y, de no existir, estuvieran impedidos de hacer nada. En consecuencia, impide que evaluemos críticamente el aspecto mítico" (Rowe, 1979, p. 20). Esta opinión evidencia que, en la crítica especializada, existe un desacuerdo al respecto de la función del mito como fuerza movilizadora de la población. Para ellos, el mito sería incapaz — por sí mismo- de movilizar a la población; sería necesario que otras ideas, más prácticas o racionalistas, se aglutinen para que tales manifestaciones se produzcan.

Para comprender la trascendencia que el mito tiene en Los ríos profundos es menester recordar que estamos ante una novela cuyo principio fundamental es expresar el pensamiento indígena y su postura frente a la historia. La idea elaborada por los antropólogos acerca de que el mito es un elemento propio de las sociedades "arcaicas" dominadas por la irracionalidad, no responde al planteamiento de Arguedas. Este propone que el pensamiento indígena puede entenderse como una alternativa de explicación cosmogónica — válida— toda vez que también posee una racionalidad y una lógica propias.

El origen de la cultura quechua, al igual que el de toda cultura, es mítico (Vega, s/f, 19-27). En ello no radica una diferencia al respecto de las culturas occidentales, quienes también provienen de una fundación sustentada en una explicación no-racionalista. Ahora bien, en las sociedades andinas, el mito posee una fuerza movilizadora fundamental y, por ende, distinta a la presentada en otras latitudes. A diferencia de lo expuesto por la mentalidad europea, donde se asegura que el mito crea sociedades incapaces de plantear programas políticos, las ideas míticas — tal y como lo plantease Mariátegui- impulsan a los hombres andinos a la acción.

Una vez asentada la importancia del mito como motor de la vida andina, es preciso señalar que el levantamiento de los colonos tiene un eminente talante mítico. Dicho aspecto proviene de que, en la memoria de los herederos de una tradición milenaria, la insurrección condensa la realidad pasada con el presente. La movilización poco a poco cobra un significado comunal que, en su 
trayectoria épica, intenta enfrentar al mal de la peste. Un hecho importante que debemos resaltar es que, al igual y como sucede con la huida de doña Felipa, desconocemos cuál fue el final de la rebelión de los colonos. Ese desconocimiento permite señalar que la posibilidad de la restauración del tiempo mítico queda abierta.

La configuración de Los ríos profundos revela que el conocimiento mítico es esencial para comprender la lógica de la vida en el Ande, pues explica la dinámica imperante entre el hombre como ser social — colectivo- y el universo. Por otra parte, es importante resaltar que el mito establece una relación directa con la "ideología”, entendida esta como un proyecto sociopolítico o una concepción particular del mundo - no como una falsa conciencia-. Los planteamientos mágico-religiosos finalmente son la representación colectiva del hombre.

Es imposible concebir al mito como el resultado verbal de un simple impulso irracional; tampoco es factible entenderlo como una forma de representación colectiva propia de las sociedades arcaicas - ajena, por tanto, a las sociedades modernas- que carece de cualquier tipo de importancia racional. Baste recordar que las sociedades con alto desarrollo económico y tecnológico también fundan sus propios mitos. El mito, por consiguiente, es una historia real cuya función es servir de "modelo" para todas las actividades humanas significativas.

Una vez que se entiende al mito como el fundamento de cualquier tipo de cosmovisión - moderna o tradicional-, es posible observar que las explicaciones mágicas de la realidad están impregnadas por la memoria histórica de cada cultura. Esto provoca que, cuando las personas imaginan el futuro de su comunidad — sobre todo, si se busca superar un presente adverso-, retomen los aspectos positivos de ese pasado común. Esta idea nos permite entender que lo planteado por Rowe implica que la idea de Arguedas no es que las movilizaciones del plural tengan en el mito su único impulso, sino que estas tienen su raíz en la misma realidad socio-económica.

El mejor ejemplo de que la configuración de Los ríos profundos responde a la lógica del pensamiento mítico es que la esperanza en el retorno de doña Felipa - acompañada por los chunchos— tiene su referente en las ideas milenaristas andinas. ${ }^{3}$ Para los indígenas andinos, la Conquista constituyó una inversión del orden cósmico; de ahí que la función del héroe mítico — doña Felipa - consista en reorganizar ese caos. En otras palabras, la cultura andina considera que solo es cuestión de tiempo para que termine la situación de pobreza y miseria padecida por los indios. Una vez producida esa restauración, serán los mistis quienes ocupen su lugar, tal y como ocurre en "El sueño del pongo" (1965), relato tomado de la tradición oral andina en el que un pongo sueña que un ángel viejo y feo le embarra excremento mientras que un ángel más joven y bello unta con miel al misti. Ante la sorpresa de este, san José ordena que se laman los cuerpos uno al otro. 
- No, padrecito mío, señor mío. Cuando nuevamente, aunque ya de otro modo, nos vimos juntos, los dos, ante nuestro gran Padre San Francisco, él volvió a mirarnos, también nuevamente, ya a ti ya a mí, largo rato. Con sus ojos que colmaban el cielo, no sé hasta qué honduras nos alcanzó, juntando la noche con el día, el olvido con la memoria. Y luego dijo: "Todo cuanto los ángeles debían hacer con ustedes ya está hecho. Ahora ¡lámanse el uno al otro! Despacio, por mucho tiempo". El viejo ángel rejuveneció a esa misma hora; sus alas recuperaron su color negro, su gran fuerza. Nuestro Padre le encomendó vigilar que su voluntad se cumpliera. (Arguedas, 1983, p. 265)

La diferencia sustancial entre la acción relatada en el cuento arguediano y la idea mítica de la restauración a la que aludimos radica en que dicha inversión se llevará a cabo en la tierra y en plena vida, no en la muerte. Ahora bien, el relato ejemplifica a cabalidad que la esperanza en la llegada de un tiempo de prosperidad y justicia forma parte de la mentalidad mítica andina.

En la cultura indígena, los intereses individuales quedan anulados frente a este postulado; lo que más interesa es el bien común. De manera que, en ese nuevo-antiguo orden, los sectores marginados podrán decidir su propio futuro. Dicha idea - el socialismo andino- considera que la unión es imprescindible para establecer una sociedad más justa e igualitaria.

En Los ríos profundos, el personaje plural culmina con la trayectoria épica del pueblo oprimido, encarnado por las chicheras y los colonos. Este hecho revela que la idea de la colectividad del mundo indio es el fundamento de la novela. Finalmente, ellos - el grupo- demuestran que son capaces de retomar su concepción mágica, plantear su fuerza colectiva y establecer la posibilidad de un cambio social. En este sentido, también tiene un talante simbólico la imagen del cuerpo desarticulado del Inkarrí. Dado que este representa la desunión de una sociedad a causa de sus opresores; la unión de sus miembros supone la unión de los marginados y el levantamiento esperado para la construcción del nuevo Perú.

\section{Notas}

1 Académico investigador del Centro de Investigaciones sobre América Latina y el Caribe (CIALC) de la Universidad Nacional Autónoma de México (UNAM).

2 El concepto utopía no existe como tal en el mundo andino. En la cosmovisión indígena, el cambio hacia una sociedad igualitaria y justa llegará indudablemente; solo hay que esperar. Para Flores Galindo "la utopía andina son los proyectos (en plural) que pretendían enfrentar esta realidad (la explotación, el sometimiento, la miseria y la muerte). Intentos de navegar contra la corriente para doblegar tanto a la dependencia como a la fragmentación. Buscar una alternativa en el encuentro entre la memoria y lo imaginario: la vuelta a la sociedad incaica y el regreso del Inca. Encontrar en la reedificación del pasado, la solución a los problemas de identidad”. (Galindo, 1986, p. 14). Las cursivas son nuestras. 
3 Utilizamos el término "milenarismo" para caracterizar el pensamiento quechua andino que, pese a no ser un concepto propio, creemos enmarca el carácter del retorno del tiempo de la libertad y la igualdad del hombre.

\section{Referencias bibliográficas}

Arguedas, José María. (1964). ¿Qué es el folklore? En Cultura y pueblo, 1 (1), 10-11. Arguedas, José María (1969). Primer Encuentro de Narradores peruanos. Lima: Casa de la Cultura del Perú.

Arguedas, José María. (1973). Los ríos profundos. Buenos Aires: Losada.

Arguedas, José María, (1983), Relatos completos, Buenos Aires, Losada.

Castro Klarén, Sara. (1973). El mundo mágico de José María Arguedas. Lima: Instituto de Estudios peruanos.

Cornejo Polar, Antonio. (1973). Los universos narrativos de José María Arguedas. Buenos Aires: Losada.

Dorfman, Ariel (1972). Imaginación y violencia en América. Barcelona: Anagrama.

Eliade, Mircea. (1967). Lo sagrado y lo profano. Madrid: Guadarrama.

Flores Galindo, Alberto. (1986). Buscando un inca: Identidad y utopía en los Andes. La Habana, Casa de las Américas.

Lienhard, Martin. (1990). La voz y su huella. Conflicto étnico-social en América Latina. La Habana: Casa de las Américas.

Rowe, William. (1979). Mito e ideología en la obra de José María Arguedas. Lima: Instituto Nacional de Cultura.

Urello, Antonio. (1974). José María Arguedas, el nuevo rostro del indio: una estructura mitico-poética. Lima: Editorial J. Mejía Baca.

Vargas Llosa, Mario. (1972). Tres notas sobre Arguedas. En Jorge Lafforgue. (ed.). Nueva novela bispanoamericana (Tomo I). Buenos Aires: Paidós.

Vega, Inca Garcilaso de la (s/f). Comentarios reales. Lima: Ediciones Nuevo Mundo. 